\title{
A saúde e os riscos dos pescadores e catadores de caranguejo da Baía de Guanabara
}

\author{
The health and risks of fishermen and crab catchers \\ of Guanabara Bay
}

M árcia Ferreira M endes Rosa ${ }^{1}$

U birajara Aluizio deO liveira M attos ${ }^{2}$

${ }^{1}$ Secretaria de Estado de Educação do Estado do Rio deJaneiro, SEE RJ, Ciep 409 Alaide Figueiredo. Estrada do Coelho, Bairro do Coelho. 24000-000 São Gonçalo RJ. marciafmendes2003@ click21.com.br ${ }^{2}$ Departamento de Engenharia Sanitária e de M eio Ambiente, Faculdade deEngenharia,

Universidade do Estado do Rio deJaneiro.
Abstract The article discusses the health, risks and the work of fishermen and crab catchers in region of APA Guapimirim in Guanabara Bay. Fishermen and crab catchers are typical informal workers, they suffer from lack of protection and working guarantee. They are exposed to working risks day by day such as accidents with fishing boat, fishing equipment, the own fish, drowning, as well as a lot of radiation and climatic variation. There are still the weight and work overload, as well as the activities done at night that increase the potential risks. A sample of 100 fishermen and crab catchers had told by quantitative qualitative research that it was possible to draw a profile of these workers. They are workers that have little schooling, $63 \%$ of these workers have incomplete elementary school and $12 \%$ are illiterate. $44 \%$ of these workers reported that they get diseases or health problems. These diseases are related to the weight overload, the long working hours and all situation of danger that they have on their work activities. As a conclusion the article identified a lot of difficulties of these workers while performing their work and realizes that is necessary to find measures to could improve their life and work conditions.

Key words Fishermen, Crab catcher, Informal work, Guanabara Bay
Resumo 0 artigo discute a saúde, os riscos e 0 trabalho dos pescadores e catadores de caranguejo da região da APA de Guapimirim na Baía de Guanabara. Eles são típicos trabalhadores informais, sem proteção e garantias trabalhistas. Estão expostos a vários riscos no seu dia a dia, como acidentescom embarcações, com osapetrechos depesca, com o próprio pescado, afogamentos, além de estarem expostos à grande radiação e variações climáticas. Há ainda a sobrecarga de peso etrabalho ea própria atividade noturna que potencializa mais os riscos. A partir de uma amostra de cem trabaIhadores, querelataram por meio de uma pesquisa exploratória e descritiva de abordagem quantiqualitativa, traçou-se um perfil dos mesmos. São trabalhadores que possuem baixa escolaridade, predominando o primeiro grau incompleto (63\%) e com $12 \%$ do total de analfabetos. U ma parcela desses trabal hadores (44\%) relataram possuir doenças ou agravos à saúde. Essas doenças estão relacionadasà sobrecarga de peso, à grandejornada de trabalho e todas as situações de periculosidade a que estão expostos em suas atividades. Foram identificadas grandes dificuldades desses trabalhadores em realizar o seu labor, havendo a necessidade urgente de encontrar medidas que possam melhorar suas condi ções de trabal ho e vida.

Palavras-chave Pescadores, Catadores de caranguejo, Trabalho informal, Baía de Guanabara 
Introdução

\section{A pesca na Baía de Guanabara}

Diariamente, navegam na Baía de Guanabara centenas de pescadores e catadores de caranguejo com seus barcos e apetrechos, retirando desse ecossistema o seu sustento e de suas famílias. É um trabalho árduo e silencioso, envolvendo trabalhadores informais e formais da região.

$A$ atividade informal desenvolvida por eles apresenta uma situação de extrema precariedade, deixando-os totalmente desprotegidos. Eles estão sujeitos a riscos de acidentes e doenças, devido ao grande esforço físico a que se submetem, variações climáticas e contato com agentes patológicos num ambiente sem saneamento. Esta situação tem se generalizado no país, indicando uma transformação do trabalho do homem, principalmente nas grandes metrópoles ${ }^{1}$.

A pesca e a cata de caranguejo são algumas das atividades informais desenvolvidas por comunidades pesqueiras e passadas de geração a geração. N a Baía de Guanabara, ainda existem os coletores de mariscos e as sirizeiras que mantêm por décadas a tradição familiar.

As atividades de pesca podem ser classificadas em artesanais e comerciais. Para Diegues ${ }^{2}$, pesca artesanal é aquela em que os pescadores autônomos, sozinhos ou em parcerias, participam diretamente da captura, usando instrumentos relativamente simples. A remuneração é feita pelo sistema tradicional de divisão da produção em "partes", sendo o produto destinado preponderantemente ao mercado. Da pesca, retiram a maior parte de sua renda, ainda que sazonalmente possam exercer atividades complementares. A organização da produção artesanal se faz basicamente por dois sistemas: o de "quinhão" ou "partes" e o de "aviamento".

Segundo Barroso ${ }^{3}$, um grande número de artes de pesca éutilizado pelos pescadores na baía, em razão da existência da diversidade dos alimentos: as redes de cerco, as redes de arrasto de portas, as redes de espera, as linhas-de-mato, 0 currico, o mergulho ou caça submarina, os currais, os covos, a arrasto-de-praia, a tarrafa e 0 puçá. Algumas dessas artes são utilizadas, às vezes, por apenas uma comunidade pesqueira.

Cerca de $45 \%$ da produção brasileira são de cunho artesanal, representando a atividade pesqueira em águas costeiras, um papel relevantena produção de alimentos para a população brasileira. Também apresenta um forte indicador social, proporcionando a oportunidade de aproxi- madamente duzentos mil empregos diretos eindiretos, gerados através da produ ução e comercialização de insumos básicos. A sazonalidade das capturas é responsável por um dos fatores que contribuem para a manutenção da atividade em padrões artesanais. Diferenças específicas e geográficas na migração de peixes, em resposta ao regime hidrológico, dão a base para o desenvolvimento das pescarias ${ }^{4}$.

0 uso de todas estas artes de pesca é extre mamente variável nas comunidades pesqueiras. $\mathrm{N}$ ota-se que as comunidades situadas no interior da baía, caracterizadas por uma pesca artesanal bem marcante, são aquelas que utilizam artes mais diversificadas (Gradim, Itaoca, M auá, Ilha do Governador). As comunidades situadas na área mais poluída (Ramos e Caju) exibem o menor número de artes de pesca utilizadas, operadas principalmente fora da baía. Comunidades da margem oriental da baía (Jurujuba e Ilha da Conceição) são dedicadas a uma pesca comercial, ainda que em modelo artesanal. As comunidades de Copacabana eltaipu são consideradas da área de abrangência da Baía de Guanabara, por situarem-se nas duas extremidades de sua zona estuarina; contudo, as artes de pesca utilizadas caracterizam uma pesca oceânica e de característica cada vez mais recreativa ${ }^{3}$.

Atualmente, existem cinco colônias de pescadores na Baía de Guanabara, conforme mostra a Tabela 1. Elas estão situadas em locais tradicionais de pesca e desembarque de pescadores.

Para o IBAM A ${ }^{5}$, coexistem na baía pelo menos seis diferentes "sistemas" pesqueiros, incluindo a pesca da sardinha boca-torta e savelha, com destinação industrial; as diferentes pescarias artesanais, voltadas para a tainha, corvina, bagre, espada, parati e outros peixes, envolvendo a maior parte do contingente de barcos e pescadores e a totalidade dos currais; a pesca do

\begin{tabular}{ll}
\hline \multicolumn{2}{l}{ Tabela 1. Colônias de pesca. } \\
\hline Colônias de pesca & \multicolumn{1}{c}{ Local } \\
\hline Z-08 & Jurujuba, Ponta da Areia, Praia \\
& Grande, Ilha da Conceição, \\
Z-09 & Gradim, Itaoca e Itambi \\
Z-10 & Magé \\
Z-11 & Ilha do Governador \\
Z-12 & Ramos \\
& Caju
\end{tabular}


camarão, com sazonalidade bem marcada, entre setembro e janeiro; a coleta do caranguejo nos manguezais; a pesca do siri, com o auxílio de puçás, visando ao processamento pelas "descarnadeiras" e, finalmente, a coleta de mexilhões, nos costões rochosos da baía oceânica, também direcionada ao processamento. Esses sistemas diferentes vêm reforçar a importância desseecossistema para todas as comunidades envolvidas.

A arte de pesca, com todas as suas sabedorias e entendimentos sobre o vento, a lua, as nuvens, é passada de geração a geração. A pesca artesanal é sempre realizada em embarcações pequenas (botes ou canoas) a remo ou à vela ou mesmo motorizadas, sem instrumentos de apoio à navegação, contando tão somente com a experiência e o saber adquiridos. Porém, devido ao grau de poluição na baía e a consequente diminuição da pesca, esse ciclo está ameaçado de prosseguir.

Além da poluição, a diminuição da pesca é resultado da pesca predatória, ou seja, da pesca realizada em períodos de defeso, ou quando é feita com material impróprio e esforço excessivo da mesma, como elevado número de pescadores ou quantidade de pescado insuficiente no ambiente de pesca.

Para Resende ${ }^{6}$, o desenvolvimento da pesca na região leste da Baía de Guanabara deu-se também devido à instalação de indústrias pesqueiras eindústria naval nessa região, o que possibilitou a renovação da frota e a instalação de portos em vários locais. Em 1980, houve o declínio da indústria pesqueira nessa região, agravado pela crescente poluição da Baía de Guanabara.

A precariedade da legislação trabalhista específica para o setor pesqueiro, especialmente aquela relacionada aos segmentos feminino e artesanal, estimula a conivência entre o pescador e 0 armador no desrespeito à legislação, agravando a ausência da cobertura assistencial e social aos pescadores. As poucas linhas de crédito se tornam restritas tanto pela falta de informação dos mesmos como pelos empecilhos impostos pelos bancos, aumentando a dificuldade de aquisição de novas embarcações e tecnologia do setor $^{6} . .0$ pescador, assim, precisa usar de sua criatividade para "driblar" a falta de recursos. Muitos aprendem a fazer suas próprias redes e consertos em seu barco.

Apesar do aumento da poluição e da diminuição da pesca, o número de pescadores da região tem aumentado ano a ano. As estimativas sobre o número oficial de pescadores da baía são bem contraditórias e deixam dúvidas devido à grande variação: estudo feito pelo IBAM A $^{5}$ apon- ta cerca de 2.200, já os estudos de Cantarino e Souza ${ }^{7}$ apontam para 5.000 , enquanto que 0 CIDS $^{8}$ indica um total de 18.000 pescadores, incluindo os registrados e não-registrados, para as cinco colônias da Baía de Guanabara.

Os pescadores sentem dificuldades no escoamento dessa produção, pois são péssimas as condições de atracação nos locais de embarque e desembarque. ParaJ ablonski, Ascondições deatracação, desembarque e comercialização são muito variáveis em todo o litoral da baía. A crescenta-sea isso o fato dequeas condições da baía de Guanaba$\mathrm{ra}$, onde a pesca ainda é realizada por um grande número de embarcações a remo, sem refrigeração ou apenas com caixas isotérmicas, para a conservação do pescado, a questão de insumos tendea ser menos importante aumentando assi $m$ a dispersão dos pontos de desembarque e de comercialização9.

Já a coleta de caranguejos constitui um universo particular no cenário da atividade pesqueira na baía, na medida em que se realiza nos manguezais enão no espelho d água eimplica processos de comercialização diretos e pulverizados, quase sempre com a participação dos próprios coletores ${ }^{10}$. A captura de caranguejos atualmente encontra-se mais restrita à região de manguezais da APA de Guapimirim, nas localidades de Itaoca, Itambi e M agé.

Essa captura éfeita predominantementecom a utilização de armadilhas (laços) formadas por tiras de plástico, colocadas sobre as tocas. 0 petrecho é conhecido como "redinha" nas demais áreas de ocorrência do Sudeste-Sul, reservandose a primeira para outra modalidade de captura utilizada em algumas regiões e que consiste em um laço na forma de forca, preso na extremidade de um pedaço de madeira. 0 catador após a cata amarra os caranguejos em cordas, cerca de dez a doze, separado por tamanhos. 0 caranguejo é vendido vivo nas ruas e feiras da cidade.

Os riscos da atividade

e a saúde do trabalhador

Segundo a Organização Internacional do Trabalho (OIT), em texto citado por $N$ eto et al. ${ }^{11}$, a pesca é reconhecidamente uma das atividades mais perigosas e coloca os pescadores em risco de mortesete vezes ao deoutros setores industriais juntos, sendo os naufrágios, condições adversas do tempo e encontro com animais aquáticos perigosos as principais causas de acidentes registradas. Com a diminuição dos estoques pesqueiros e devido ao estresse provocado pelos baixos rendimentos, muitos pescadores tentam 
compensar a situação indo cada vez mais longe, permanecendo mais tempo nos locais de pesca e menosprezando as condições adversas do meio, permitindo, assim, 0 aumento do risco de ocorrência de acidentes, esses muitas das vezes graves ou até fatais.

Segundo Dall 'OCa ${ }^{12}$, em seu trabalho com os pescadores de M ato Grosso do Sul, entre as trinta queixas mais frequentes relatadas, destacaramse as dores de origem neuromusculares e articulares, traduzidas por dores nos pulsos, braços, juntas, ombros, costas, peito, coluna, câimbras ou dores pelo corpo em geral, podendo estar relacionadas ao desconforto físico sentido pelos trabalhadores quando do desenvolvimento de suas atividades. Outras queixas muito declaradas estão relacionadas a problemas de origem respiratória, como bronquites, pneumonias, gripes e resfriados, traduzidos por crises de tosse, falta de ar e obstrução nasal.

Nos textos da OIT, citados por Parmeggian$\mathrm{ni}^{13}$, já se apontavam várias enfermidades relativas ao trabalho com a pesca, como bursites, tenossinovites, doenças do aparelho digestivo, tensão nervosa, excesso de consumo de álcool e/ou fumo, provocando enfermidades respiratórias, sinusites, cáries dentárias, dermatites originadas pelo contato com óleo diesel e perda de audição, provocada pela exposição a níveis deruído excessivos. Os estudos realizados junto à categoria revelam os mais variadostipos deadoecimento, com influência negativa em sua vida econômica e social.

$\mathrm{N}$ a região de $\mathrm{M}$ agé (RJ), Chaves et al..$^{14}$ realizaram avaliações em processos de trabalho e vida dos pescadores, tendo mostrado casos de agravo à saúde, inclusive mortes, com doenças de veiculação hídrica e de vetores, e transtornos mentais. Para os autores, as ocorrências acidentárias se devem basicamente às questões econômicas e de total desamparo a que essa categoria se encontra.

Torres $^{15}$ relata as especificidades do envel he cimento em comunidades pesqueiras de Abade (PA), localizadas no estuário amazônico, onde a atividade se dá em ambiente hostil para a saúde. Ele detectou casos de afogamentos, distúrbios do sono e outros problemas, como insegurança e uso de drogas.

Em estudo promovido por Schinder et al. ${ }^{16}$, destinado a avaliar o perfil de saúde de 101 pescadores de $\mathrm{M}$ ar del Plata, houve correlação significativa entrea exposição dos trabal hadores aos fatores de riscos no ambiente de trabalho, como umidade, vento, radiação solar, ruído, calor, frio e sintomas reumáticos, bronquites, úlceras di- gestivas, problemas de origem geniturinárias, transtornos circulatórios, tabagismo e enfermidades dermatológicas, entre outros.

Pereira ${ }^{17}$ aponta casos de transtornos psiquiátricos como esquizofrenia, uso abusivo do álcool e fumo em pescadores residentes em Vigia (PA). Estudo promovido por Rodrigues et al. ${ }^{18}$ indica que foram detectadas bactérias do gênero vibrio em feridas nos membros inferiores de pescadores do município de Raposa (MA).

Através desses trabalhos, fica evidente que essa categoria pode ter vários agravos à saúde relacionados a seu trabal ho e condições de vida em diversas regiões do país, o que pode indicar que este quadro também se repete em outras localidades brasileiras, em particular, nas comunidades pesqueiras da Baía de Guanabara. A ausência de estudos sobre esse tema de extrema relevância para a saúde col etiva de populações trabalhadoras do Rio de Janeiro motivou a realização de uma pesquisa que teve como objetivo traçar um perfil destes trabalhadores, identificar as suas condições de trabalho e vida e os impactos destas condições na sua saúde ${ }^{19}$.

Este artigo discute a saúde, os riscos e 0 trabalho dos pescadores e catadores de caranguejo da região daAPA deGuapimirim na Baía deGuanabara, região compreendida pelos municípios de São Gonçalo, Itaboraí, M agé e Guapimirim.

\section{M etodologia}

A pesquisa foi realizada em comunidades pesqueiras da região da APA de Guapimirim no período de 2004/2005.

Inicialmente, foi feito um levantamento bibliográfico sobre o tema proposto, através de artigos, livros, teses, sites, etc. A seguir, foi realizada uma pesquisa de campo, de caráter quantiqualitativo, com uma amostra aleatória de cem trabalhadores (oitenta pescadores e vinte catadores de caranguejos) das comunidades de São Gonçalo, I taboraí, M agée Guapimirim, utilizando questionários semiabertos nas entrevistas. Além disso, foram realizadas visitas aos locais para observação e investigação dos processos de trabalho, dosfatores deriscos deacidentes edoenças, condições de moradia e contatos com os líderes locais das associações de pesca e de moradores da região estudada.

Os cem trabalhadores (pescadores e catadores de caranguejo) foram entrevistados no próprio local de trabalho, ou seja, nas praias, próximo aos mangues e canais da região enos locais de 
venda do pescado. Esses trabalhadoresforam convidados a participar dessa pesquisa, que tinha como objetivo conhecer mais a atividade pesqueira eas dificuldades por eles encontradas. Todos os participantes alfabetizados assinaram o termo de consentimento livre e esclarecido, no qual eram apresentadas as condições de participação voluntária da pesquisa e do anonimato, sendo que os analfabetosforam esclarecidos verbalmentedetodo o processo, optando ou não pela participação.

Os dados foram sistematizados no aplicativo Epi Info versão 6.04, constituindo um banco de dados da amostra, o que permitiu elaborar diversas tabelas com cruzamentos das informações e fazer a análise das mesmas. Os questionários do tipo semiaberto permitiram uma maior participação desses trabalhadores, através do relato de suas experiências e dos problemas que ocorrem no dia a dia, colocan do demaneira mais efetiva as suas condições de saúde, trabalho e vida, e aspectos particulares da atividade. As análises das informações foram realizadas utilizando-se os dados estatísticos mostrados nas tabelas, juntamente com os depoimentos feitos pel os trabalhadores, possibilitando a identificação de aspectos relevantes sobre as suas condições de trabal ho e vida geradoras de riscos e agravos à saúde, bem como um maior entendimento da atividade pesqueira artesanal desenvolvida na Baía de Guanabara.

\section{Resultadosediscussão}

As informações obtidas através dos questionários aplicados e depoimentos possibilitaram traçar o perfil dessa amostra de trabalhadores, bem como conhecer as suas condições de saúde, trabalho e vida.

0 grupo pesquisado era constituído de 99 homens ( 79 pescadores e vinte catadores) e ape nas uma mulher (pescadora). A predominância masculina deve-se às características das atividades, que requerem um grande esforço físico na sua realização, cabendo às mulheres a participação mais intensa na venda do caranguejo, limpeza e preparação das redes e apetrechos e da retirada da carne de siri (sirizeiras).

Outro dado importante é a idade desse trabalhador, apresentada na Tabela 2.

Observa-se que a maioria dos pescadores $(70,1 \%)$ se encontranafaixa superior aos 36 anos de idade. Dos catadores são mais jovens, $65 \%$ têm até quarenta anos, se concentrando mais na faixa entre 31 e 35 anos (25\%).

\begin{tabular}{lrccrr}
\hline \multicolumn{6}{l}{ Tabela 2. A ocupação x a idade do trabalhador. } \\
\hline \multicolumn{1}{c}{ Idade } & Pescador & \multicolumn{1}{c}{$\%$} & Catador & $\%$ & Total \\
\hline $18-25$ & 7 & $8,8 \%$ & 3 & $15,0 \%$ & $10 \%$ \\
$26-30$ & 6 & $7,5 \%$ & 3 & $15,0 \%$ & $9,0 \%$ \\
$31-35$ & 9 & $11,3 \%$ & 5 & $25,0 \%$ & $14 \%$ \\
$36-40$ & 15 & $18,8 \%$ & 2 & $10,0 \%$ & $17 \%$ \\
$41-45$ & 14 & $17,5 \%$ & 2 & $10,0 \%$ & $16 \%$ \\
$46-50$ & 4 & $5,0 \%$ & 3 & $15,0 \%$ & $7,0 \%$ \\
$51-55$ & 14 & $17,5 \%$ & 1 & $5,0 \%$ & $15,0 \%$ \\
$56-59$ & 4 & $5.0 \%$ & 0 & $0 \%$ & $4,0 \%$ \\
$60+$ & 5 & $6,3 \%$ & 1 & $5,0 \%$ & $6,0 \%$ \\
$<18$ & 2 & $2,5 \%$ & 0 & $0 \%$ & $2 \%$ \\
Total & 80 & & 20 & & $100 \%$ \\
\hline
\end{tabular}

Fonte: Rosa ${ }^{19}$.

Para os menores de dezoito anos, a situação não é diferente; eles já entram na pesca por que não conseguem ser inseridos no mercado de trabalho formal e por que há também uma enorme tradição em passar os conhecimentos sobre a pesca para os filhos ${ }^{3,6}$; assim, há sempre uma renovação, os que param e os que iniciam na vida da pesca $3,6,20$.

Outro fato observado é que, na amostra, não houve catadores com menos de dezoito anos; contudo, esse fato não significa que não exista catador nessa faixa etária - é bem inferior a presença de menores no mangue e maior na venda das cordinhas de caranguejo nas feiras e ruas da cidade.

A escolaridade dos pescadores e catadores de caranguejo é baixa, ou seja, a maioria possui até o primeiro grau incompleto (63\%) e $12 \%$ são analfabetos. Os analfabetos estão distribuídos nas faixas etárias, inclusive entre os mais jovens. Esse percentual ainda pode ser mais alto, visto que muitos dos que assinam seu nome não sabem ler. Para eles, uma melhoria de vida está relacionada a uma melhor educação, ou seja, um futuro melhor.

Muitos pescadores gostariam que seus filhos tivessem uma outra vida, apesar da forte tradição que há em passar os conhecimentos de pai para filho: Prefiro que meus filhos estudem e que saiam fora da pesca. (Sr. F, pescador, 38 anos)

A falta de uma profissão e de estudo são determinantes para a fixação desse homem nesse ambiente, além das instalações de indústrias pesqueiras enavais na região $0^{6}$. Além do seu sustento, a maioria desses trabalhadores (64\%) garantem 
a sobrevivência de seus familiares com a remuneração do seu trabalho, acarretando uma carga maior de responsabilidade desses trabalhadores em relação à manutenção de suas famílias.

As condições de vida são difíceis para esses trabal hadores que atuam na informalidade eque convivem com a instabilidade da pesca e da precariedade das relações detrabal ho. Uma das principaisqueixas dos pescadores éa diminuição crescente da pesca. Segundo Vergara ${ }^{21}$, a pesca predatória é apontada como um dos principais fatores que contribuem para tal redução. Para a Feema ${ }^{22}$, a atividade pesqueira foi sendo reduzida devido ao assoreamento. As causas deste processo podem ser atribuídas aos aterros, à transformação de rios em canais e à destruição dos manguezais e ao lançamento de resíduos. Para Barroso ${ }^{3}$, os recursos pesqueiros da baía foram diminuindo de maneira muito intensiva, o que pode ser atribuído à baixa qualidade das águas e ao excessivo esforço de pesca.

Com 0 acidente na Baía de Guanabara em 2000, provocado pelo derramamento de óleo, muitos pescadores relataram que a situação dos que sobrevivem da pesca piorou: Cada dia a vida está pior. Depois do acidente, as coisas pioraram muito por aqui. (Sr. AFS, 55 anos). Esta situação foi relatada pelo 0 Globo ${ }^{23}$ : "Os estragos causados pelo vazamento de óleo de 1,3 milhão delitros de óleo na Baía de Guanabara", em 18 de janeiro de 2000, que afetou manguezais, praias, aves e peixes, até hoje não foram compensados".

Para Amador ${ }^{24}$, épreciso compreender o funcionamento, a importância ea produtividadedos ecossistemas que existiram e ainda remanescem em seu interior e em suas margens, avaliar o grau de degradação ambiental atualmente apresentado, os riscos de extinção, se essa degradação não for detida, assim como os projetos de recuperação ea repercussão destes na melhoria efetiva desse ecossistema e na qualidade de suas águas.

Os pescadores, em sua maioria (58\%), moram em casa própria, em geral, próxima à praia, ou mesmo, em alguns casos, em áreas na própria praia. Muitos são posseiros e outros vivem em terrenos da M arinha. As casas são bem simples ou apenas barracos improvisados, onde guardam seus apetrechos da pesca, os isopores e materiais necessários do dia a dia. Já os catadores de caranguejo moram também próximo ao mangue, em áreas mal saneadas e insalubres, como ocorre com os pescadores (Figura 1). Alguns mantêm casa ou barracos próximos a rios da região, sofrendo perdas em épocas de cheiase enchentes.

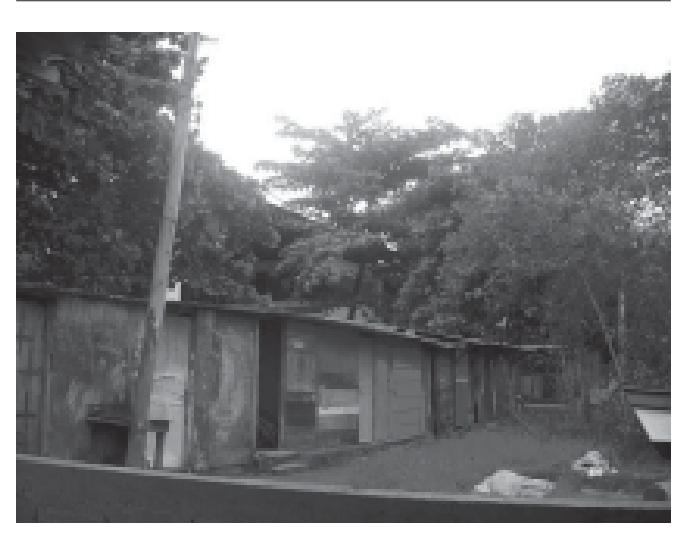

Figura 1. Moradias dos pescadores (Porto Novo, São Gonçalo).

A moradia próxima do ambiente de trabalho elimina a necessidade de transporte para a maioria $(69 \%)$. Porém, para uma parcela dos catadores de caranguejo (12\%), chegar ao local ideal para a coleta necessita de barcos, navegando pelo rio Caceribu. A questão de estar próximo ao mar é muito importante, devido ao alto custo do transporte, que onera em muito o valor do pescado, etambém pela facilidade em manusear todos os apetrechos de pesca e de manter o barco perto de casa.

As condições de trabalho podem ser diagnosticadas por uma carga de trabalho expressiva. Os pescadores e catadores ficam muito tempo no mar e ainda preparam os apetrechos para a pesca, fazendo acertos e manutenção da rede e de outros materiais. A duração da jornada diária para $57 \%$ varia de oito a doze horas no mar ou mangue, sendo longa e cansativa, e outros $34 \%$ têm uma jornada de doze a dezesseis horas.

A atividade de pesca noturna é ainda mais desgastante e perigosa, pois o pescador retorna do mar de madrugada e ainda participa da venda do seu pescado, nos leilões na praia, em geral para atravessadores (29\%) e comerciantes locais (21\%).

Essa forma de remuneração (diária) éa mais utilizada ( $81 \%$ ), que consisteem vender o pescado logo assim que se chega na praia, no comércio e feiras da região. A procura nesses locais de desembarque de pescado é grande. Ainda antes de amanhecer, muitas pessoas de várias regiões e atravessadores (29\%) já se encontram nesses locais para pegar o seu peixe fresco, participando deleilões (21\%), por um preço bem mais barato. 
Quando eles não conseguem vender todo o pescado, alguns se encaminham para as ruas ( $8 \%$ ) e feiras da região (6\%).

A renda évariável para $78,8 \%$ dos pescadores e $100 \%$ dos catadores, ou seja, depende do que eles conseguem do mar ou mangue, sendo que $67 \%$ dos trabal hadores recebem até dois salários mínimos com a pesca.

A informalidade e o desemprego são situações comuns para os pescadores e catadores de caranguejo, com o predomínio de uma situação de extrema precariedade e falta de proteção ${ }^{1}$.

0 desemprego está bem presente entre esses trabalhadores; $62 \%$ dos entrevistados já estiveram desempregados. Para 38\%, a pesca e a cata de caranguejos são o seu emprego, o seu ganhapão permanente, a única saída para a sua sobrevivência. 0 desemprego está distribuído por todas as faixas etárias, mas é entre 36 e 45 anos que setorna mais expressivo (33\%). M uitos nem consideram a pesca como um emprego: Desempregado, somos todos. (Sr. GA, catador, 29 anos)

Os pescadores e catadores de caranguejo gostariam de ter um trabalho formal, com carteira assinada $(21 \%)$, podendo receber todos os direitos trabal histas assegurados ( $25 \%$ ) e que lhes proporcionasse um salário fixo (16\%). Já estiveram no setor formal $68,8 \%$ dos pescadores, enquanto que $40 \%$ dos catadores já passaram por este setor, desempenhando atividades principalmenteno setor terciário (51\%). A complementação de renda com atividade paral ela é necessária para esses trabal hadores em épocas em que o pescado está mais escasso ou na época do defeso. Cinquenta por cento não desempenham atividade paralela contra outros $50 \%$ que têm outra atividade eventual ou fixa. Conciliar uma atividade fixa é mais difícil para o pescador, que precisa estar disponível em boa parte do dia e da noite.

A maioria (66\%) não possui registro de autonomia. Pagar a autonomia para muitos é algo difícil, pois eles têm dificuldade de juntar qualquer montante. Basicamente, o dinheiro arrecadado é usado nas suas necessidades básicas diárias.

Quando adoecem, os pescadores e catadores de caranguejo recorrem ao serviço público para atendimento médico (84\%). Muitos reclamam do péssimo atendimento dos hospitais e postos de saúde da região, da falta de médicos e serviços especializados.

Doscem pescadores entrevistados, $44 \%$ relataram problemas e agravos à saúde e uma rotina sofridaesilenciosa. As condições adversas da atividade do mar e mangue são colocadas de forma unânime como os maiores riscos enfrentados. A saúde é o bem mais precioso, pois nada pode ser feito seo corpo ou a mente adoece; sinais desobrecarga de trabalho são expressos e identificados nas reclamações de dores e problemas da coluna. Os pescadores e catadores de caranguejo se expõem a grandes variações de temperatura, como excesso deradiação solar efrio intenso, desempenhando uma jornada de trabal ho excessiva.

$A$ atividade pesqueira pode ser considerada potencialmente perigosa segundo o Código $\mathrm{Na}$ cional de Atividades Econômicas (CNAE, 2000/ 2002) por expor os trabal hadores a possíveis riscos de acidentes com embarcações, afogamentos, acidentes com os apetrechos de pesca, esforços físicos acima dos limites do corpo, problemas de postura inadequada, mudanças climáticas, trabalho noturno, ruído, acidentes com o pescado, contato com agentes patológicos em ambiente mal saneado e outros.

Há também a questão da baixa autoestima que leva muitos trabalhadores a terem problemas com o álcool e o fumo 13,15,17. Muitos recorrem à bebida para conseguir aliviar os sintomas da depressão e as dificuldades inerentes do oficio. A bebidaémuito utilizada para "esquentar"e "passar o tempo".0 equilíbrio emocional é importante para o trabalhador que passa a noite no mar, muitas vezes sozinho. É dele que parte a observação do cardume e das ações e atitudes para se ter êxito em sua pescaria.

Os riscos desses trabalhadores são narrados e absorvidos com uma certa "aceitação", ou seja, o trabalhador tem a real dimensão dos perigos que passa, porém sabe que precisa desse trabalho eincorpora essa rotina no seu dia a dia: Você sai para pescar enão sabe se volta. (Sr. AFS, pescador)

As falas desses trabalhadores mostram um pouco dessa situação de extrema periculosidade e de precariedade. Eles contam com a "sorte" para conseguir semanter, driblar a falta de recursos disponíveis, enfrentar a falta de segurança no mar ou no mangue e as condições de risco, além do ambiente degradado. 0 defeso é um dos poucos direitos que Ihes asseguram uma certa "proteção" no período mais crítico: Se sofrer algum acidente, não vou receber nada. (Sr. CG, catador)

0 ambiente do mangue se torna mais perigoso, sendo necessário muita atenção e experiência: No mangue, tem muita ponta de pau, há lugares onde se você não passar rápido, fica agarrado. (Sr. A, catador)

A pesar de toda situação de risco, émuito baixo 0 uso de algum tipo deEPI entre eles.

0 uso de EPI é maior entre os pescadores ( $46,3 \%$ contra $20 \%$ entre os catadores). 0 cata- 
dor, além dos riscos de acidentes no rio, ainda enfrenta inúmeros riscos no mangue, com a vegetação, com os insetos, com cobras e objetos pontudos na lama do mangue. 0 catador de caranguejo faz uso de óleo queimado para se proteger dos insetos do mangue e não usa outros equipamentos de proteção como luvas e botas. 0 uso deEPI émaior na faixa entre 36 equarenta anos de idade ( $17 \%$ ) e 41 e 45 anos ( $16 \%$ ). N esse caso, denota-se a importância da experiência do mar para a prevenção de lesões. $M$ as ainda esse uso é extremamente baixo, em relação aos riscos inerentes da função. Os riscos no interior da sociedade são desiguais ${ }^{25,26}$, atingindo as populações mais desfavorecidas, como as comunidades pesqueiras do entorno da Baía de Guanabara ${ }^{25,26}$.

O uso contínuo de óleo queimado como forma de prevenção ao ataque de mosquitos e outros insetos podelevar esse trabal hador a ter problemas sérios na pele e até intoxicação ${ }^{13}$, pois partedessas substâncias são absorvidas pela pele.

0 uso de equipamento de proteção, como capas, luvas, botas, colete salva-vida, lanterna, filtro-solar, entre outros, é considerado caro por esses trabalhadores: É difícil usar equipamento de proteção. (Sr. J. da S.)

0 trabalho dos pescadores, por ser extremamente desgastante, pela exposição excessiva à radiação e variações de temperatura, uso de bebida e fumo e jornada noturna, possibilita o envelhecimento precoce ${ }^{15}$, sendo sentido pelo próprio pescador: A desvantagem de ser pescador é ficar velho rápido. (Sr. R. da S., 37 anos)

Cinquenta edois por centos dos pescadorese catadores de caranguejo não se afastaram do trabalho quando estiveram doentes ou acidentados, pois a maioria precisa trabal har mesmo assim, devido a sua condição informal. Durante as entrevistas, foi observado que alguns trabalhadores estavam doentes ou tinham sofrido acidentes recentes, porém relataram que não podiam deixar detrabalhar. Treze por cento já seafastaram por acidente e $35 \%$, por doença. Os acidentes mais comuns são com a embarcação, com o próprio material de pesca e com o ferrão do bagre. No mangue, os acidentes mais comuns são cortes com a própria foice, usada para cortar a vegetação, corte com cacos de vidro elatase picadas de animais. Porém, $55 \%$ dos pescadores e catadores expressam o perigo do mau tempo, dos ventos fortes e temporais no mar.

A discriminação social eas desigualdades que dela decorrem têm influência determinante no estado de saúde das populações afetadas ${ }^{27}$. Essas pessoas, além de ter vários agravos a sua saúde decorrentes da situação social, não encontram amparo quando adoecem ou se acidentam. A realidade cruel desses trabalhadores é retratada nas falas: Se você parar quando tiver doente ou acidentado, vai morrer de fome. (Sr. J.)

As principais queixas desses trabalhadores são em relação ao desgastefísico; para 31,3\% dos pescadores, o desgaste físico é uma preocupação a mais. A quantidade de vezes que eles lançam e puxam a rede pode causar, além do cansaço físi$\mathrm{co}$, males e doenças dos ossos e coluna ${ }^{12}$. Para $60 \%$ dos catadores de caranguejo, o trabalho no mangue é extremamente cansativo. A caminho para o mangue, eles necessitam remar muito e depois enfrentar, além da lama, os insetos e a própria vegetação local. Q uanto à queixa de ataque de animais, ela é mais evidente para o catador de caranguejo (30\%), que encontra todas essas adversidades, contra $5 \%$ dos pescadores.

Para $55 \%$ dos pescadores, há queixas com relação à embarcação, que vai desde problemas mecânicos a acidentes com outras embarcações. 0 pescador sem muitos recursos se arrisca no mar com barcos e botes sem nenhuma segurança e, muitas vezes, passa por várias dificuldades, sendo auxiliado por outros pescadores: As embarcações não oferecem segurança e os recursos são poucos para melhorar. (Sr. JB, pescador)

0 trabalho diário e a sobrecarga são reclamações de $88,8 \%$ dos pescadores; para o catador de caranguejo, que expõe a imensa dificuldade em permanecer durante horas no mangue, enfrentando diversas situações de risco, esse percentual é mais alto (95\%).

\section{Os principais agravos à saúde dos pescadores e catadores de caranguejo}

A Tabela 3 mostra os principais agravos à saúde relatados por esses trabalhadores.

É possível observar que as maiores reclamações são com relação aos problemas articulatórioseneuromusculares, o queevidencia a prática de um trabalho desgastante, aos problemas posturais e ao excesso de esforço físico, refletidos em dores nas costas, coluna, braços e pernas. Os problemas respiratórios, traduzidos por pneumonias etuberculoses, estão relacionados à grande exposição às variações climáticas e agentes patológicos e também à deficiência alimentar. Esse trabalhador mal alimentado equefaz uso abusivo deálcool aumenta as chances de adoecer. As doenças ou agravos à saúde indicados na Tabela 3 são citados por outros autores ${ }^{12-18}$ como as principais queixas dos pescadores em diversas regiões. 
Tabela 3. Queixas e agravos à saúde.

\begin{tabular}{lr}
\hline \multicolumn{1}{c}{ Doença } & freq \\
\hline Coluna e dores nas costas/hérnia de disco/joelho & 18 \\
Pneumonia e tuberculose & 9 \\
H ipertensão/coração & 7 \\
Gastrite, úlcera, problemas no estômago & 5 \\
Problemas na perna/varizes & 4 \\
Sequelas com acidente de barco & 4 \\
Dores de cabeça, cansaço e sono & 3 \\
Visão & 2 \\
Íngua e hérnia & 2 \\
Doenças infectocontagiosas (hepatite, leptospirose) & 2 \\
Estresse e alcoolismo & 2 \\
Cálculo renal & 1 \\
Alergia & 1 \\
Câncer & 1 \\
Diabete & 1 \\
Total & 44 \\
\hline
\end{tabular}

Fonte: Rosa ${ }^{19}$.
São trabalhadores que podem ter agravos a sua saúde devido ao esforço excessivo, aos problemas posturais e aos movimentos repetitivos, ocasionando doenças neuromusculares, problemas no sistema respiratório, traduzidos por sinusite, pneumonia e tuberculose, entre outras doenças já destacadas. Essas situações foram descritas de forma quase unânime pelos pescadores, que percebem os riscos, porém precisam arriscar a vida diariamente no mar ou mangue.

A pesca na Baía de Guanabara resiste apesar da intensa degradação e esses trabal hadores precisam de um esforço maior para compensar a diminuição do pescado edo caranguejo no mangue. Para isso, além de uma longa jornada de trabalho para conseguir o máximo de aproveitamento no mar ou no mangue, eles recorrem a outras atividades para buscar a sobrevivência. São atividades informais, como "bicos", quecomplementam a renda desses trabalhadores da pesca. A realidade dura do dia a dia muitas das vezes não érecompensada, pois nem sempre se consegue pescar algo ou o suficiente para pagar o óleo e o gelo utilizados. São trabalhadores que não têm um horário definido para pescar. Eles sofrem com a precariedade do trabalho informal, sem garantias e sem direitos. Para $25 \%$ da amostra, o sonho é ter carteira assinada e, dessa forma, ter mais segurança, comprar a prazo, poder se afastar quando estiver doente ou acidentado.

Os pescadores mais velhos sabem como é difícil sair da pesca, ainda mais que dificilmentetambém poderão ser inseridos no mercado formal, devido à baixa escolaridade e a própria idade.

A informalidade numa dessas comunidades éo trabal ho mais evidente e praticado. É a forma com que as pessoas lidam com a vida e a sobrevivência. Não é uma forma menos nobre que 0 formal, porém, conclusivamente, émais penoso, mais sacrificante e, de certa forma, mais injusta. A informalidade da prática, além de retirar os direitos do cidadão, também leva esse trabalhador a se expor a muitos riscos e ter agravos que se refletem na sua saúde.

\section{Colaboradores}

M FR Rosa trabalhou na pesquisa, metodologia e redação e UAO Mattos trabalhou na concepção, redação final e revisão. 


\section{Referências}

1. Ramalho JP, Arrochellas MH, organizadores. Desenvolvimento, subsistência e trabalho informal no Brasil. São Paulo: Cortez; 2004.

2. Diegues ACS. A pesca artesanal no litoral brasileiro: cenários e estratégias para sua sobrevivência. Proposta: Experiência em educação popular 1988; 38:2-24.

3. Barroso LV. Aspectos da atividade da pesca na Baía de Guanabara. Rio de Janeiro: s/n; 2000.

4. Instituto Brasileiro do M eio Ambiente e dos Recursos Naturais Renováveis. Diagnóstico Ambiental do Território Fluminense (Estado do Rio de Janeiro). Rio de Janeiro: IBAM A; 2000.

5. Instituto Brasileiro do M eio Ambiente e dos Recursos Naturais Renováveis. Evolução da Aquicultura e Pesca Segundo Categorias. Rio de Janeiro: IBAM A; 2002.

6. Resende AT. A pesca e sua questão sócio-ambiental dentro da Região M etropolitana do Rio de Janeiro. Rio de Janeiro: UERJ/FFP; 2003.

7. Cantarino AAA, Souza DS. Valoração econômica dos benefícios alcançados pela despoluição da Baía de Guanabara por ETEs domésticas. Rio de Janeiro: PPE/COPPE/UFRJ; 2000. [Mimeo]

8. Centro Internacional de Desenvolvimento Sustentável. Baía de Guanabara, Dossiê Sócio-Ambiental Rio de Janeiro: Escola Brasileira de Administração Pública, Fundação Getúlio Vargas; 2000.

9. Jablonski S, Azevedo AF, Moreira LHA, Silva OCA M onitoramento da atividade pesqueira na Baía de Guanabara como subsídio para a avaliação de impactos ambientais e a gestão da pesca. Rio de Janeiro: IBAMA/FEM AR; 2001. [Relatório preliminar]

10. Jablonski S, Azevedo AF, Moreira LHA, Silva OCA. Levantamento de dados da atividade pesqueira na Baía de Guanabara como subsídio para a avaliação de impactos ambientais e a gestão da pesca. Rio de Janeiro: IBAM A; 2002.

11. Neto DG, Cordeiro R, Haddad V. Causas de acidentes de trabalho ocorridos em pescadores profissionais artesanais do município de Araguacema-TO. Botucatu: Faculdade de M edicina, Universidade Paulista; 2002.

12. Dall'O ca AV. Aspectos sócio-econômicos, de trabalho e de saúde de pescadores do M ato Grosso do Sul [dissertação]. Campo Grande (MS): Universidade Federal do M ato Grosso do Sul; 2004.

13. Parmeaggiani L. Enciclopedia de Salud y Seguridad en el trabajo. Ginebra: Oficina Internacional del Trabajo; 1989.

14. Chaves TCO, Rangel Sant'Anna FCR. Avaliação da situação de trabalho e condições de vida dos pescadores de Magé- RJ. In: Anais do VII Congresso Brasileiro de Saúde Coletiva. Brasília: Abrasco; 2003.

15. Torres VLS. Saúde, pesca e envelhecimento no estuário amazônico. In: Anais do VII Congresso Brasileiro de Saúde Coletiva. Brasília: Abrasco; 2003.
16. Schinder EO, Pili N, Vachino M, Spillman CRE, Petersen A, Vergara S. Estudios epidemiológico del perfil de salud de pescadores de Mar del Plata: factores de riesgos ligados al ambiente laboral. C.M. Publ. M éd [periódico na Internet] 1992 [acessado 2005 jan 15];5(1):[cerca de 11 p.]. Disponível em: http://bases.biremi.br/sgi.bin/wxslind.exe/iah

17. Pereira RAC. Os isqueiros no pantanal de M ato Grosso do Sul, Brasil: uma abordagem sócio-econômica, ambiental e legal [dissertação]. Braślia (DF): Universidade de Brasília; 2001.

18. Rodrigues SMA, Gonçalves EGR, M ello DM, Oliveira EG, Hofer E. Pesquisa de bactérias do gênero vibrio em feridas cutâneas de pescadores no município de Raposa-M A. R. Socied. Bras. Med. Trop. [periódico na Internet] 2001 [acessado 2005 mai 06];34(5):[cerca de 5 p.]. Disponível em: http:// www.scielo.br/pdf/rsbmt/v34n5/5988.pdf

19. Rosa MFM. As condições de trabalho e saúde dos pescadores e catadores de caranguejos da APA de Guapimirim, RJ [dissertação]. Rio de Janeiro (RJ): FEN/ UERJ; 2005.

20. Barroso LV. Uma comunidade pesqueira na Baía de Guanabara. In: Anais do 3o Congresso Brasileiro de Defesa do M eio Ambiente; 1989; Rio de Janeiro.

21. Vergara WL, Maciel NC, Annibal S. Fauna de manguezais da Baía de Guanabara. In: Anais do $20^{\circ}$ Congresso Brasileiro de Zoologia; 1994; Rio de Janeiro.

22. Fundação Estadual de Engenharia do M eio Ambiente. Projeto de Recuperação Gradual do Ecossistema da Baía de Guanabara. Rio de Janeiro: FEEM A; 1988. [Relatório técnico]

23. Baía: 5 anos depois, ainda há danos a reparar. 0 Globo 2005; 17 jan; p.14.

24. Amador ES. Roteiro de visita à Baía de Guanabara. Caderno de Educação Ambiental II 2001; 127-150.

25. Beck U. From Industrial society to the risk society: questions of survival, social structure and ecological enlightenment. Theory, Culture \& Society 1992; 9:97-123.

26. Layrargues PP. Educação para a Gestão Ambiental. Caderno de Educação Ambiental II 2001; 151-177.

27. $M$ achado $H$. Áreas de conflito. In: Leandro $M E$, Araújo M M, Costa M, organizadores. Actas do Colóquio Internacional Saúde e Discriminação Social. Braga: Instituto de Ciências Sociais, Universidade do M inho; 2002. p. 65-68. [favor localizar essa referência no corpo do artigo]

Artigo apresentado em 09/02/2007

Aprovado em 01/11/2007

Versão final apresentada em 05/12/2007 